\title{
Gendered risk factors associated with self-harm mortality among youth in South Africa, 2006 - 2014
}

\author{
N de Wet, $\mathrm{PhD}$ \\ Demography and Population Studies, Schools of Social Sciences and Public Health, University of the Witwatersrand, Johannesburg, South Africa
}

Corresponding author: $N$ de Wet (nicole.dewet@wits.ac.za)

\begin{abstract}
Background. Despite efforts to reduce self-harm mortality, death rates remain high, with almost $12 \%$ of all youth deaths in South Africa (SA) attributed to this cause. There are gendered differences in causes of death among youth, but little is known about the sex-specific risk factors. Objective. To identify the levels and sex-specific determinants of self-harm mortality among youth in SA.

Methods. This was a cross-sectional study of SA death notification forms from 2006 to 2014. Descriptive and analytical statistical techniques were used, including cause-specific mortality rates, proportional mortality ratios and logistic regression models.

Results. A total of 1122 youth (15 - 24 years of age) deaths due to self-harm causes were reported over the study period, during which rates of self-harm mortality increased. More deaths of males $(n=818)$ than females $(n=304)$ were reported. Almost $60 \%$ of deaths $(p<0.05)$ were of 20 - 24 -year-olds, and $46.4 \%(p<0.05)$ of those who died had a secondary education. Almost $10 \%$ of females $(p<0.05)$ were pregnant at the time of death. Hanging was the most common type of self-harm mortality among males $(79.2 \%)$ and females $(49.3 \%)$. While $11.0 \%(n=90)$ of self-harm deaths of males were due to poisoning, more females used this method $(39.8 \%, n=121)$. The probability of self-harm mortality for males increased according to certain provinces of residence. For females the odds were higher for those who were pregnant (odds ratio (OR) $1.3 ; p<0.05)$ and non-South African (OR 1.7; $p<0.05)$ and had secondary education (OR 1.4; $p<0.05)$.

Conclusions. The study showed gender differentials in the determinants of self-harm mortality among youth in SA. For this reason, uniform approaches to awareness campaigns need to be altered to address the specific needs of youth. While males have higher rates than females, the prevalence of self-harm mortality in pregnant females is of concern and needs to be addressed specifically, as it relates not only to suicidal ideation and behaviour but also to youth sexual and reproductive health programmes in the country.
\end{abstract}

S Afr Med J 2017;107(12):1132-1136. DOI:10.7196/SAMJ.2017.v107i12.12652

Self-harm (suicide) behaviours are particularly worrisome among youth. Recent statistics suggest that $17 \%$ of all deaths in South Africa (SA) are due to self-harm, and more than half of these are among youth (20 - 24 years old) and young adults (25 - 39 years old). ${ }^{[1,2]}$ Further, a study showed that $7.2 \%$ of children and adolescents in SA reported suicidal ideation in the past month, and $3.2 \%$ of adolescents admitted to having attempted suicide..$^{[3]}$ The youth of SA are fundamental to the social, economic and political development of the population. For this reason, research addressing the challenges to their health and survival is much needed. Social research has identified psychological distresses, including depression, anxiety and bullying, as determinants of self-harm behaviours among youth. ${ }^{[4-6]}$ Based on this, efforts have been made to reduce this behaviour, including the introduction of Teen Suicide Prevention Week, when the public are educated on prevention strategies and early warning signs. ${ }^{[7]}$ During this week a number of non-governmental organisations, schools, places of employment and community centres offer free counselling services. ${ }^{[2]}$ In addition to this initiative, other programmes and policies in the country also attempt to reduce selfharm mortality. The South African Depression and Anxiety Group, which serves as an advocacy and support network for individuals suffering from various mental health disorders, offers free telephonic counselling services and referrals to medical professionals. ${ }^{\left[{ }^{[8}\right.}$ Also, Life Line Southern Africa provides a free 24-hour crisis intervention service available nationally. ${ }^{[8]}$ The National Youth Policy (2015 2020) overarches these initiatives by setting the goal of ensuring that youth in SA are able to be responsible for their own wellbeing, which includes their physical and mental health. ${ }^{[9]}$ However, despite these strategies the problem persists, with an increase in overall self-harm mortality rates from $8 \%$ in 1999 to $12 \%$ in $2009 .{ }^{[2,10]}$

The prevalence and determinants of health and mortality patterns among youth (15 - 24 years of age) differ by sex. Research has shown that the prevalence of infectious disease is higher among young females in SA than among males, while injury-related mortality is higher among males. ${ }^{[11,12]}$ It has also been found that gendered differences in socioeconomic status, as well as cultural norms and practices, contribute to the health discrepancies between males and females. ${ }^{[13-15]}$ With regard to self-harm mortality, little other than rates is known of the sex-specific determinants among youth in SA.

\section{Objective}

To identify the sex-specific risk factors associated with self-harm mortality among youth in SA. Although under-reporting of suicide is a concern noted by many researchers, ${ }^{[16-18]}$ this study pooled together 9 years of data in order to obtain a sample size reasonable enough for robust statistical analysis.

\section{Methods}

Self-harm is defined as any act of intentional self-poisoning or selfinjury, regardless of motivation, and self-harm mortality is a death resulting from such an act. ${ }^{[19]}$ This study examined self-harm mortality among youth for the period 2006 - 2014. Both males and females were included, and data were from the national death notification forms (DNFs) collated by Statistics South Africa. These data are anonymised by Statistics South Africa before becoming available for public download, i.e. the study was an analysis of secondary data 
available in the public domain. The data were not collected by the author and there was no need for institutional review board approval. The study sought to identify sexspecific determinants of self-harm/suicide among youth in SA.

All deaths from self-harm causes of youth aged 15 - 24 years $(N=1122)$ were analysed. All DNFs where there was completed information on the age, sex and cause of death (ICD-10 (International Statistical Classification of Diseases and Related Health Problems, 10th revision) codes X60 - X84) were included. The percentage of cases with missing information on sex over the period was $0.5 \%(n=2104)$. These forms were not included in the analysis.

Analysis of specific types of self-harm makes it possible to quantify the extent to which these behaviours are contributing to the mortality of youth and to examine differences by sex. In the ICD-10 these types have been grouped into various forms of poisoning (X60 - X69), hanging, strangulation and suffocation (X70), drowning and submersion (X71), firearm use (X72 - X74), explosive material or use of fire (X75 - X77), sharp or blunt object use (X78 - X79), jumping or falling from a height or a moving object (X80 - X81), and other means (X82 X84). A full list of the ICD-10 codes can be found online (http://apps.who.int/classifications/icd10/browse/2010/en).

Frequencies, percentages, cause-specific mortality rates and proportional mortality ratios (PMRs) were used to describe the differences in self-harm mortality by sex, age group, highest level of education, province of death, and pregnancy status among females. Logistic regression models showing odds ratios (ORs) were used to identify sexspecific risk factors.

\section{Results}

Trends in self-harm mortality among youth in SA from 2006 to 2014 are shown in Fig. 1. The graph shows that males had consistently higher rates of self-harm mortality than females. Further, rates for male youth have been increasing since 2010, while rates among females declined in 2013 before increasing in 2014. For all youth there was a noticeable decline in 2010 , followed by an increase.

Table 1 shows that the prevalence of selfharm mortality among males was highest in the older age group (20 - 24 years), while among females it was highest in the younger age group (15 - 19 years). Youth with secondary education had the highest PMR among both males and females. In every province there was a higher percentage of male deaths compared with females. KwaZulu-Natal had the highest proportions of mortality among males and females, and the proportion of self-harm mortality was higher among youth who were SA citizens than among those whose citizenship is unknown. Of females who died from selfharm causes, almost $10 \%$ were pregnant.

Hanging was the main cause of self-harm mortality among youth (Table 2), for males and females and in both of the age groups. Poisoning was the second most common cause. However, among males causes other than hanging constituted $\sim 20 \%$ of deaths, while among females there was less variability, with poisoning accounting for $40.2 \%$ of deaths among 15 - 19-year-olds and $39.2 \%$ among 20 - 24-year-olds. Use of firearms was uncommon among both males and females (3.9\% and $2.3 \%$, respectively)

The odds of self-harm mortality according to pregnancy status, province of residence, citizenship status, education and age among females are shown in Fig. 2. Among females, secondary education (OR 1.4 (95\% confidence interval (CI) 0.4 - 1.4)), being a non-SA citizen (OR 1.7 (95\% CI 0.3 - 1.4)), residing in the Northern Cape (OR 1.7 (95\% CI 0.6 - 0.8)) or KwaZulu-Natal (OR 1.4 (95\% CI $0.3-2.4)$ ) and being pregnant (OR 1.3 (95\% CI 0.3 - 1.3)) were associated with increased odds of self-harm mortality.

The odds of self-harm mortality among males according to province of residence, citizenship status, education and age are shown in Fig. 3. Among males, residing in the Northern Cape (OR 1.9 (1.7 - 2.1)), KwaZulu-Natal (OR 1.5 (1.3 - 1.7)), North West (OR $1.75(1.3$ - 1.7)) and Mpumalanga (OR $1.3(1.2-1.7)$ ) were associated with increased odds of self-harm mortality.

\section{Discussion}

The purpose of this study was to identify the sex-specific determinants of youth mortality due to self-harm behaviours in SA. Males had higher rates of self-harm mortality than females. This result is similar to a report showing that $75 \%$ of all self-harm deaths in SA were of males. ${ }^{[20]} \mathrm{A}$ more recent study found that $80 \%$ of all self-harm deaths in the

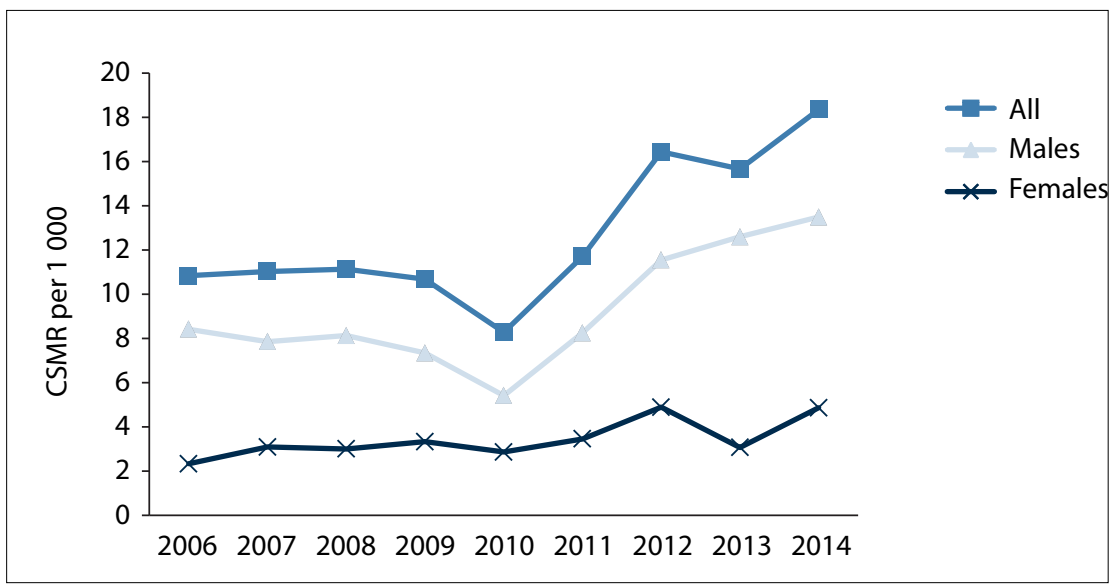

Fig. 1. Trends in self-harm mortality among youth (age 15 - 24 years) by sex in South Africa, 2006 2014. (CSMR = cause-specific mortality rate. $)$

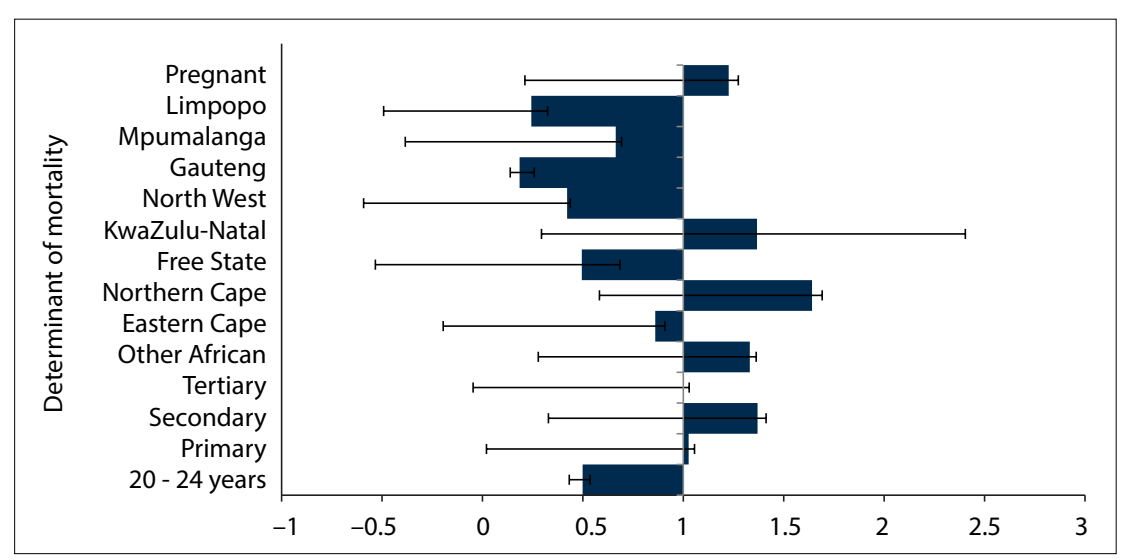

Fig. 2. Adjusted odds ratios of self-harm mortality according to pregnancy status, province of residence, citizenship status, education and age among young (15-24 years of age) females in South Africa. 
Table 1. Frequency $(n)$, row percentage (\%) and PMR distribution of self-harm mortality by individual characteristics of youth in SA, $2006-2014$

\begin{tabular}{|c|c|c|c|c|c|c|c|c|}
\hline \multirow[b]{2}{*}{ Characteristic } & \multicolumn{2}{|c|}{ Total $(N=1122)$} & \multicolumn{3}{|c|}{ Males $(N=818)$} & \multicolumn{3}{|c|}{ Females $(N=304)$} \\
\hline & $n$ & PMR & $n$ & $\%$ & PMR & $n$ & $\%$ & PMR \\
\hline \multicolumn{9}{|l|}{ Age (yr) } \\
\hline $15-19$ & 456 & 40.6 & 272 & 59.7 & 33.3 & 184 & 40.4 & 60.5 \\
\hline $20-24$ & 666 & 59.3 & 546 & 82.0 & 66.8 & 120 & 18.0 & 39.5 \\
\hline$p$-value & \multicolumn{2}{|c|}{0.000} & \multicolumn{3}{|c|}{0.000} & \multicolumn{3}{|c|}{0.000} \\
\hline \multicolumn{9}{|c|}{ Highest level of education } \\
\hline None & 23 & 2.1 & 19 & 82.6 & 2.3 & 4 & 17.4 & 1.3 \\
\hline Primary & 99 & 8.8 & 75 & 75.8 & 9.2 & 24 & 24.2 & 7.9 \\
\hline Secondary & 521 & 46.4 & 360 & 69.1 & 44.0 & 161 & 30.9 & 53.0 \\
\hline Tertiary & 98 & 8.7 & 76 & 77.6 & 9.3 & 22 & 22.5 & 7.2 \\
\hline Unknown & 381 & 33.9 & 288 & 75.6 & 35.2 & 93 & 24.4 & 30.6 \\
\hline$p$-value & \multicolumn{2}{|c|}{0.000} & \multicolumn{3}{|c|}{0.000} & \multicolumn{3}{|c|}{0.000} \\
\hline \multicolumn{9}{|l|}{ Province of death } \\
\hline Western Cape & 120 & 10.7 & 95 & 79.2 & 11.6 & 25 & 20.8 & 8.2 \\
\hline Eastern Cape & 119 & 10.6 & 71 & 59.7 & 8.7 & 48 & 40.3 & 15.8 \\
\hline Northern Cape & 147 & 13.1 & 105 & 71.4 & 12.8 & 42 & 28.6 & 13.8 \\
\hline Free State & 32 & 2.9 & 23 & 71.9 & 2.8 & 9 & 28.1 & 3.0 \\
\hline KwaZulu-Natal & 441 & 39.2 & 312 & 70.8 & 38.1 & 129 & 29.3 & 42.4 \\
\hline North West & 54 & 4.8 & 46 & 85.2 & 5.6 & 8 & 14.8 & 2.6 \\
\hline Gauteng & 34 & 3.0 & 26 & 76.5 & 3.2 & 8 & 23.6 & 2.6 \\
\hline Mpumalanga & 95 & 8.5 & 75 & 79.0 & 9.2 & 20 & 21.1 & 6.6 \\
\hline Limpopo & 66 & 5.9 & 52 & 78.8 & 6.4 & 14 & 21.2 & 4.6 \\
\hline Outside SA & 3 & 0.3 & 3 & 100 & 0.4 & 0 & 0 & 0 \\
\hline Unknown & 11 & 1.0 & 10 & 90.9 & 1.2 & 1 & 9.1 & 0.3 \\
\hline$p$-value & \multicolumn{2}{|c|}{0.000} & \multicolumn{3}{|c|}{0.000} & \multicolumn{3}{|c|}{0.000} \\
\hline \multicolumn{9}{|c|}{ Pregnancy status (females) } \\
\hline Yes & 8 & 9.3 & - & - & - & 8 & 100 & 9.3 \\
\hline No & 78 & 90.7 & - & - & - & 78 & 100 & 90.7 \\
\hline Total & 86 & & - & - & - & 86 & & \\
\hline$p$-value & \multicolumn{2}{|c|}{0.000} & & & & \multicolumn{3}{|c|}{0.000} \\
\hline
\end{tabular}

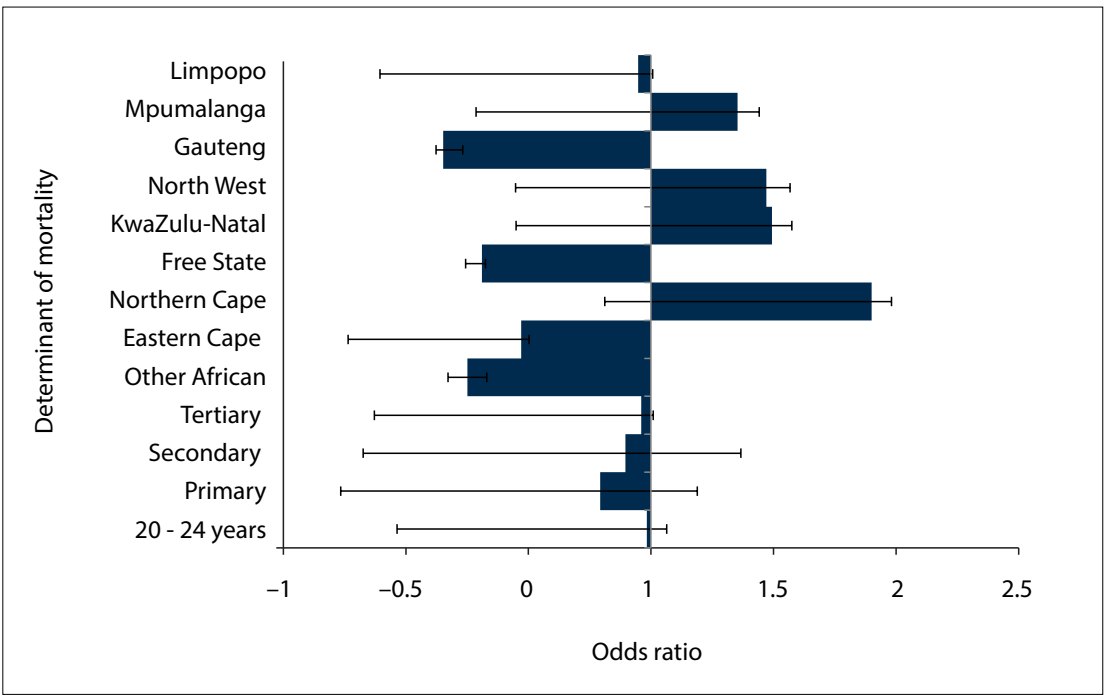

Fig. 3. Adjusted odds ratios of self-harm mortality according to province of residence, citizenship status, education and age among young (15-24 years of age) males in South Africa.

country were of males. ${ }^{[21]}$ A possible reason for this is related to gender differences in health-seeking behaviour. While globally females have higher levels of mental health illness related to self- harm behaviours, such as depression, they also have better health- seeking behaviours for these illnesses than males, which reduce the risk of self-harm mortality. ${ }^{[22]}$ Other behaviours that exacerbate self-harm are the excessive use of alcohol and illicit drug use, which are more prevalent among males (3.6\%) than females (2.2\%). ${ }^{[23,24]}$

Hanging was the main cause of self-harm mortality among youth for both males and females. This is consistent with an older study in SA on the causes of self-harm mortality in all age groups. ${ }^{[25]} \mathrm{A}$ possible reason for hanging being relatively common is that it is regarded as a 'clean method' that does not cause harm to the body (e.g. bloodshed and dismemberment), requires little planning, and is an accessible method that does not require weapons or pharmaceuticals, which can be difficult to access. ${ }^{[26]}$ In contrast to these findings, however, one study found that pesticide poisoning is currently the most common method of self-harm mortality worldwide. ${ }^{[27]}$ Among youth in SA, poisoning was found to be the second most common cause of self-harm 
Table 2. Types of self-harm mortality by sex and age group, 2006 - 2014

\begin{tabular}{|c|c|c|c|c|c|c|}
\hline \multirow{2}{*}{$\begin{array}{l}\text { Age group } \\
\text { (yr) }\end{array}$} & \multicolumn{2}{|l|}{ Males } & \multicolumn{2}{|l|}{ Females } & \multicolumn{2}{|l|}{ Total } \\
\hline & Cause & Deaths, $n(\%)$ & Cause & Deaths, $n(\%)$ & Cause & Deaths, $n(\%)$ \\
\hline \multicolumn{7}{|l|}{$15-24$} \\
\hline 1 & Hanging & $652(79.7)$ & Hanging & $150(49.3)$ & Hanging & $802(71.5)$ \\
\hline 2 & Poisoning & $90(11.0)$ & Poisoning & $121(39.8)$ & Poisoning & $211(18.8)$ \\
\hline 3 & Firearm & $32(3.9)$ & Other & $18(5.9)$ & Other & $46(4.1)$ \\
\hline 4 & Other & $28(3.4)$ & Firearm & $7(2.3)$ & Firearm & $39(3.5)$ \\
\hline 5 & Jumping/falling & $5(0.6)$ & Drowning & $6(2.0)$ & Drowning & $9(0.8)$ \\
\hline 6 & Explosive material/fire & $4(0.5)$ & Jumping/falling & $2(0.7)$ & Jumping/falling & $7(0.6)$ \\
\hline 7 & Object (sharp/blunt) & $4(0.5)$ & Explosive material/fire & 0 & Explosive material/fire & $4(0.4)$ \\
\hline 8 & Drowning & $3(0.3)$ & Object (sharp/blunt) & 0 & Object (sharp/blunt) & $4(0.4)$ \\
\hline Total & & 818 & & 304 & & 1122 \\
\hline \multicolumn{7}{|l|}{$15-19$} \\
\hline 1 & Hanging & $215(79.0)$ & Hanging & $85(46.2)$ & Hanging & $300(65.8)$ \\
\hline 2 & Poisoning & $28(10.3)$ & Poisoning & $74(40.2)$ & Poisoning & $102(22.4)$ \\
\hline 3 & Firearm & $13(4.8)$ & Other & $12(6.5)$ & Other & $25(5.5)$ \\
\hline 4 & Other & $13(4.8)$ & Drowning & $6(3.3)$ & Firearm & $19(4.2)$ \\
\hline 5 & Drowning & $1(0.4)$ & Firearm & $6(3.3)$ & Drowning & $7(1.5)$ \\
\hline 6 & Explosive material/fire & $1(0.4)$ & Jumping/falling & $1(0.5)$ & Jumping/falling & $2(0.4)$ \\
\hline 7 & Jumping/falling & $1(0.4)$ & Explosive material/fire & 0 & Explosive material/fire & $1(0.2)$ \\
\hline Total & & 272 & & 184 & & 456 \\
\hline \multicolumn{7}{|l|}{$20-24$} \\
\hline 1 & Hanging & $437(80.0)$ & Hanging & $65(54.2)$ & Hanging & $502(75.4)$ \\
\hline 2 & Poisoning & $62(11.4)$ & Poisoning & $47(39.2)$ & Poisoning & $109(16.4)$ \\
\hline 3 & Firearm & $19(3.5)$ & Other & $6(5.0)$ & Other & $21(3.2)$ \\
\hline 4 & Other & $15(2.8)$ & Firearm & $1(0.8)$ & Firearm & $20(3.0)$ \\
\hline 5 & Object (sharp/blunt) & $4(0.7)$ & Jumping/falling & $1(0.8)$ & Jumping/falling & $5(0.8)$ \\
\hline 6 & Jumping/falling & $4(0.7)$ & Drowning & 0 & Object (sharp/blunt) & $4(0.6)$ \\
\hline 7 & Explosive material/fire & $3(0.6)$ & Explosive material/fire & 0 & Explosive material/fire & $3(0.5)$ \\
\hline 8 & Drowning & $2(0.4)$ & Object (sharp/blunt) & 0 & Drowning & $2(0.3)$ \\
\hline Total & & 546 & & 120 & & 666 \\
\hline
\end{tabular}

mortality among both males and females. Poisons used in SA are often commonly used household items, including bleach, detergents and pesticides, to which females have daily access. ${ }^{[28]}$

With regard to age, rates of self-harm mortality were higher among older youth aged 20 - 24 years than in the younger group. Other studies conducted in SA have reported similar results. ${ }^{[29,30]}$ Youth face a number of social, economic and health challenges that contribute to self-harm behaviours, including the emotional and mental stress associated with high unemployment rates, poverty, HIV/AIDS, educational difficulties, physical and emotional abuse, parental separation and substance abuse. ${ }^{[31,32]}$

Pregnancy increases the likelihood that young females in SA will commit suicide. Fertility rates among youth in SA are high, with one study showing that $36.6 \%$ of females aged $15-24$ years have at least one child. ${ }^{[33]}$ Further, of women aged 15 - 24 years, a high proportion (32.4\%) are single mothers. ${ }^{[33]}$ Self-harm ideation and behaviours could therefore be the result of young women feeling abandoned by their partners, stigmatised by their families, and constrained financially.

The study findings are of particular significance to policies, programmes and the medical community. The programmes mentioned earlier in the article and the National Youth Policy (2015 2020) would benefit from the results of this study by identifying subgroups that are at increased risk of self-harm mortality, so that strategies can be expanded and itemised to reach specific groups of youth. The medical community can benefit from the results in two ways. First, medical fields such as psychiatry can be informed of key characteristics of youth who are most likely to suffer from mental health illnesses and engage in self-harm behaviours. Second, population-based studies such as this contribute to the ongoing education of the medical community in recognising and treating mental health illnesses.

\section{Study limitations}

The study is subject to limitations. First, self-harm is reported on the DNFs and determined by medical professionals. The true intention of the act on the part of the deceased is unknown. Second, there are limited variables available for analysis on DNFs, and for this reason, social and mental health determinants of self-harm mortality could not be ascertained. Finally, because few cases are reported annually, data needed to be pooled to increase the sample size for this study. The problem associated with this is that annual changes in the sociopolitical environment and their influences on self-harm mortality could not be analysed.

\section{Conclusion}

There is a difference in levels of self-harm mortality between young males and females in SA, suggesting that a uniform approach to awareness and prevention programmes will not reduce mortality rates. Further, since self-harm behaviours are intrinsically linked to mental health disorders, sex-specific approaches to the detection and treatment of these illnesses should be developed. Pregnant youth especially should be screened for mental health disorders, including 
depression, as a means of preventing self-harm mortality. With cause-specific mortality rates increasing among youth, there is also a need for more social support to assist those who are struggling. While national awareness campaigns do exist, such as the Mental Health Awareness Month in October each year, more is needed in the form of peer groups and counselling services across the country. Finally, the results of this study indicate that a few areas of future research can be recommended. First, more research on the self-harm behaviours of pregnant youth needs to be done. This study could not ascertain whether some of these deaths were not botched attempts at pregnancy termination that resulted in death, rather than intentional acts of suicide. Identifying the intention of these behaviours is pivotal to the implementation of successful prevention strategies. Second, a study that includes more information on the social and sociopolitical determinants of self-harm mortality would explain and better predict trends seen in youth mortality over time. Finally, a qualitative study of youth with suicidal ideation and those who have attempted selfharm behaviours in the past would help explain the epidemiology of self-harm mortality risk factors reported in this article.

Acknowledgements. None.

Author contributions. Sole author.

Funding. This work was partially funded by the Andrew W Mellon Foundation and the University of the Witwatersrand, Johannesburg, South Africa.

Conflicts of interest. None.

1. Matzopoulos R, Prinsloo M, Bradshaw D, et al. The Injury Mortality Survey: A National Study of Injury Mortality Levels and Causes in South Africa in 2009. Cape Town: Medical Research Council, 2013.

2. De la Rey M. Suicide rates in South Africa. Interview in Cape Talk online, 16 February 2016. http://www. . De la Rey M. Suicide rates in South Africa. Interview in Cape Talk online, 16 February 2016. httt://www.
capetalk.co.za/articles/11594/suicide-accounts-for-17-percent-of-all-deaths-in-southafrica (accessed 4 capetalk.co.z

3. Cluver L, Orkin M, Boyes ME, Sherr L. Child and adolescent suicide attempts, suicidal behavior, and adverse childhood experiences in South Africa: A prospective study. J Adolesc Health 2015;57(1):52-59. https://doi.org/10.1016/j.jadohealth.2015.03.001

. Chesney E, Goodwin GM, Fazel S. Risks of all-cause and suicide mortality in mental disorders: A metareview. World Psychiatry 2014;13(2):153-160. https://doi.org/10.1002/wps.20128

5. Aleman A, Denys D. A road map for suicide research and prevention. Nature 2014;509(7501):421-423. https://doi.org/10.1038/509421a

6. Cluver L, Gardner F, Operario D. Poverty and psychological health among AIDS-orphaned children in Cape Town, South Africa. AIDS Care 2009;21(6):732-741. https://doi.org/10.1080/09540120802511885

7. South African Depression and Anxiety Group. Feelings of failure: Teen suicide prevention week. http:// www.sadag.org/index.php?option=com_content\&view=article\&id=1924:teen-suicide-prevention-
worid WwW.sadag.org/index.php?option $=$ com_content\&view=aric
week\&catid=111\&Itemid=1362017 (accessed 25 May 2017). 8. Schlebusch L. Suicide prevention: A proposed national strategy for South Africa. Afr J Psychiatry

9. Office of the Presidency, Republic of South Africa. National Youth Policy 2015 - 2020. www.thepresidency. Office of the Presidency, Republic of South Africa. Nationa/
gov.za/download/file/fid/58 (accessed 7 November 2017)

10. Naidoo SS, Schlebusch L. Sociodemographic characteristics of persons committing suicide in Durban, South Africa: 2006 - 2007. Afr J Prim Health Care Fam Med 2014;6(1):1-7. https://doi.org/10.4102/ phcfm.v6i1.568
11. Shisana O, Rehle T, Simbayi L, et al. South African National HIV Prevalence, Incidence and Behaviour Survey, 2012. Pretoria: Human Sciences Research Council, 2014.

12. Seedat M, van Niekerk A, Jewkes R, Suffla S, Ratele K. Violence and injuries in South Africa: Prioritising an agenda for prevention. Lancet 2009;374(9694):1011-1022. https://doi.org/10.1016/S0140an agenda for

13. Rivas-Drake D, Seaton EK, Markstrom C, et al. Ethnic and racial identity in adolescence: Implications for psychosocial, academic, and health outcomes. Child Dev 2014;85(1):40-57. https://doi.org/10.1111/ cdev. 12200

14. Gibbs A, Sikweyiya Y, Jewkes R. 'Men value their dignity': Securing respect and identity construction in urban informal settlements in South Africa. Glob Health Action 2014;7(1). https://doi.org/10.3402 gha.v7.23676

15. Varga CA. How gender roles influence sexual and reproductive health among South African adolescents. Stud Fam Plann 2003;34(3):160-172. https://doi.org/10.1111/j.1728-4465.2003.00160.x

16. Reid AE, Hendricks MK, Groenewald P, Bradshaw D. Where do children die and what are the causes? Under-5 deaths in the Metro West geographical service area of the Western Cape, South Africa, 2011. S Afr Med J 2016;106(4):359-364. https://doi.org/10.7196/SAMJ.2016.v106i4.10521

17. Joubert J, Rao C, Bradshaw D, Vos T, Lopez AD. Evaluating the quality of national mortality statistics from civil registration in South Africa, 1997 - 2007. PLoS One 2013;8(5):e64592. https://doi.org/10.1371/ journal.pone.0064592

18. Groenewald P, Bradshaw D, Neethling I, et al. Linking mortuary data improves vital statistics on cause Groenewald P, Bradshaw D, Neethling I, et al. Linking mortuary data improves vital statistics on cause
of death of children under five years in the Western Cape Province of South Africa. Trop Med Int Health of death of children under five years in the Western Cape

19. Hawton K, Harriss L, Hall S, Simkin S, Bale E, Bond A. Deliberate self-harm in Oxford, 1990 - 2000: A time of change in patient characteristics. Psychol Med 2003;33(6):987-995. https://doi.org/10.1017 S0033291703007943

20. World Health Organization. Suicide Rates by Gender and Race, South Africa. Geneva: WHO, 2007.

21. Bantjes J, Kagee A. Epidemiology of suicide in South Africa: Setting an agenda for future research. S Afr J Psychol 2013;43(2):238-251. https://doi.org/10.1177/0081246313482627

22. Bjerkeset $\mathrm{O}$, Romundstad P, Gunnell D. Gender differences in the association of mixed anxiety and depression with suicide. Br J Psychiatry 2008;192(6):474-475. https://doi.org/10.1192/bjp. bp. 107.045203

23. Degenhardt L, Whiteford HA, Ferrari AJ, et al. Global burden of disease attributable to illicit drug use and dependence: Findings from the Global Burden of Disease Study 2010. Lancet 2013;382(9904):1564-1574. https://doi.org/10.1016/S0140-6736(13)61530-5

24. Peltzer K, Ramlagan S, Johnson BD, Phaswana-Mafuya N. Illicit drug use and treatment in South Africa: Peltzer K, Ramlagan S, Johnson BD, Phaswana-Mafuya N. Illicit drug use and treatment in South Aftici
A review. Subst Use Misuse 2010;45(13):2221-2243. https://doi.org/10.3109/10826084.2010.481594

25. Meel B. Epidemiology of suicide by hanging in Transkei, South Africa. Am J Forensic Med Pathol Meel B. Epidemiology of suicide by hanging in Transkei, South Af

2006;27(1):75-78. https://doi.org/10.1097/01.paf.0000202738.28446.4a
26. Biddle L, Donovan J, Owen-Smith A, et al. Factors influencing the decision to use hanging as . Biddle L, Donovan J, Owen-Smith A, et al. Factors influencing the decision to use hanging as a
method of suicide: Qualitative study. Br J Psychiatry 2010;197(4):320-325. https://doi.org/10.1192/bjp. bp. 109.076349

27. Bertolote JM, Fleischmann A, Butchart A, Besbelli N. Suicide, suicide attempts and pesticides: A major hidden public health problem. Bull World Health Organ 2006;84(4):260. https://doi.org/10.1590/S004296862006000400004

28. Shilubane HN, Ruiter RA, Bos AE, van den Borne B, James S, Reddy PS. Psychosocial correlates of suicidal ideation in rural South African adolescents. Child Psychiatry Hum Dev 2014;45(2):153-162. https://doi.org/10.1007/s10578-013-0387-5

29. Burrows S, Laflamme L. Suicide among urban South African adolescents. Int J Adolesc Med Health 2008;20(4):519-528. https://doi.org/10.1515/IJAMH.2008.20.4.519

30. Burrows S, Vaez M, Laflamme L. Sex-specific suicide mortality in the South African urban context The role of age, race, and geographical location. Scand J Public Health 2007;35(2):133-139. https://doi. org/10.1080/14034940600975773

31. Randall JR, Doku D, Wilson ML, Peltzer K. Suicidal behaviour and related risk factors among schoolaged youth in the Republic of Benin. PLoS One 2014;9(2):e88233. https://doi.org/10.1371/journal pone. 0088233

32. Shilubane HN, Ruiter RA, van den Borne B, Sewpaul R, James S, Reddy PS. Suicide and related health risk behaviours among school learners in South Africa: Results from the 2002 and 2008 national youth risk behaviour surveys. BMC Public Health 2013;13(1):926. https://doi.org/10.1186/1471 2458-13-926

33. Kara R, Maharaj P. Childbearing among young people in South Africa: Findings from the National Income Dynamics Study. South Afr J Demogr 2015;16(1):57-85,

Accepted 24 August 2017 